\title{
EFFECT OF REFRIGERATION AND FROZEN STORAGE ON THE CAMPYLOBACTER JEJUNI RECOVERY FROM NATURALLY CONTAMINATED BROILER CARCASSES
}

\author{
Maike T. Maziero, Tereza Cristina R. M. de Oliveira
}

Universidade Estadual de Londrina, Centro de Ciências Agrárias, Departamento de Ciência e Tecnologia de Alimentos, Londrina, PR, Brasil.

Submitted: March 16, 2009; Approved: November 07, 2009.

\begin{abstract}
Campylobacter jejuni is the most common thermophilic Campylobacter associated with human enteritis in many countries. Broilers and their by-products are the main sources for human enteritis. Refrigeration and freezing are used to control bacterial growth in foods. The effect of these interventions on survival of Campylobacter jejuni is yet not quite understood. This study evaluated the effect of storage temperature on the survival of $C$. jejuni in chicken meat stored for seven days at $4{ }^{\circ} \mathrm{C}$ and for 28 days at $-20^{\circ} \mathrm{C}$. The influence of selective enrichment on recovery of Campylobacter was also evaluated. Thirty fresh chicken meat samples were analyzed and $93.3 \%$ was contaminated with termotolerant Campylobacter spp. with average count of $3.08 \mathrm{Log} 10 \mathrm{CFU} / \mathrm{g}$ on direct plating. After refrigeration, $53.3 \%$ of the analyzed samples tested positive for Campylobacter and the average count was $1.19 \mathrm{Log} 10 \mathrm{CFU} / \mathrm{g}$. After storage at $-20^{\circ} \mathrm{C}$, $36.6 \%$ of the samples were positive with a verage count of $0.75 \mathrm{Log} 10 \mathrm{CFU} / \mathrm{g}$. C. jejuni was detected after enrichment, respectively, in $50 \%$ of the fresh, $36.7 \%$ of the refrigerated and $33.3 \%$ of the frozen meat samples analyzed. No difference was detected for the recovery of $C$. jejuni from fresh, refrigerated or frozen samples after selective enrichment, showing that this microorganism can survive under the tested storage conditions.
\end{abstract}

Key words: Campylobacter, frozen storage, refrigeration, broiler meat.

\section{INTRODUCTION}

Campylobacter spp cause human bacterial gastroenteritis and are significant foodborne pathogens. C. jejuni is the most common species responsible for human illness. Although rarely fatal, C. jejuni infections are associated with post-infection complications including Guillian-Barré Syndrome, Miller Fisher Syndrome, reactive arthritis, Reiter's Syndrome and haemolytic uraemic syndrome $(8,21,23,27)$.

C. jejuni is part of the saprophyte intestinal flora of poultry, swine, and cattle and the epidemiological evidence suggests that these animals may be reservoirs for strains that infect humans. Poultry and poultry products have been implicated as a major source of Campylobacter infection in humans (15). The prevalence of Campylobacter in raw poultry products ranges from 0 to $100 \%(6,16)$. Although Brazil is the world's largest chicken exporter, little information has been published on the occurrence of Campylobacter spp. in Brazilian chicken products. Studies carried out on retail chicken in São Paulo State during 1986 and 1987 showed that $47.5 \%$ and $62.2 \%$, respectively, of the analyzed samples were contaminated with Campylobacter spp. $(1,18)$.

\footnotetext{
*Corresponding Author. Mailing address: Universidade Estadual de Londrina, UEL, Departamento de Ciência e Tecnologia de Alimentos, Rodovia Celso Garcia Cid (PR 445), Km 380, Campus Universitário, Caixa Postal 6001, CEP 86051-990, Londrina-Paraná.; Tel: (43) 3371-4565 Fax: (43) 3371-4080.; E-mail: terezaoliveira@yahoo.com
} 
Refrigeration and freezing are used to control bacterial growth in foods. The effect of these interventions on survival of $C$. jejuni is not entirely clear. Different authors showed that counts of $C$. jejuni in poultry carcasses decrease during refrigeration or freezing $(2,30)$ and several studies demonstrated that Campylobacter survive in raw and cooked poultry meat during refrigerated or frozen storage $(3,4,9,17$, 25, 26, 29). Many factors can cause injury or death of Campylobacter cells such as ice nucleation, dehydration or oxidative stress (24). The detection of viable cells after chilled or frozen storage is important as the $C$. jejuni infectious dose is thought to be about 500 cells.

The detection of thermotolerant Campylobacter in foods requires selective enrichment broths at $42^{\circ} \mathrm{C}$ under microaerophilic atmosphere (5) thus providing adequate conditions for growth of thermotolerant species, protection against toxic oxygen derivatives and recovery of injured cells (10).

This study evaluated the effect of refrigeration and freezing on survival of $C$. jejuni in chicken carcasses as well as the influence of selective enrichment on recovery of $C$. jejuni.

\section{MATERIALS AND METHODS}

\section{Sample Preparation}

Thirty broiler carcasses obtained from a commercial processing plant between September and November 2006 were analyzed. The carcasses were collected less than one hour after packaging. From each carcass three different 25-g aliquots were prepared with portions of skin from cloacae, neck, leg and drumstick. One of the $25-\mathrm{g}$ aliquots was analyzed on the same day (fresh samples), the second one was analyzed after seven days at $4^{\circ} \mathrm{C}$ and the third one after 28 days at $-20^{\circ} \mathrm{C}$. These conditions were chosen to simulate the conditions to which poultry meat is exposed during processing and subsequent commercial storage. The $25-\mathrm{g}$ aliquots were placed in Stomacher 400 filter bags containing $225 \mathrm{ml}$ of buffered peptone water (HiMedia Laboratories, Mumbai, India). The samples and diluent were mixed in Stomacher 400 (Lab System Ltd, USA) for 60 seconds. The sample rinses were used for microbiological analysis. For each experiment, 25-g samples of skin obtained from chicken carcasses not contaminated with Campylobacter spp. were spiked with approximately $100 \mathrm{CFU}$ of $C$. jejuni ATCC 33291 (Adolfo Lutz Institute, São Paulo, Brazil) and used as positive control. Uncontaminated and uninoculated 25-g samples of chicken skin were used as negative controls. The microbiological analysis of the controls was performed as described below.

\section{Thermotolerant Campylobacter spp count by direct plating}

The modified Bolton agar described by Franchin; Aidoo and Batista (13) was prepared as follows: dehydrated Bolton broth (CM 983; Oxoid, Basingstoke, Hampshire, England) was suspended in water, added $1.5 \%$ agar-agar (HiMedia Laboratories, Mumbai, India) and $0.5 \mathrm{~g} / \mathrm{L}$ ferrous sulphate (J. T. Baker, Germany). After adjusting to $\mathrm{pH} 7,5$. and sterilization by autoclaving at $121^{\circ} \mathrm{C}$ for $15 \mathrm{~min}$., the medium was cooled to $50^{\circ} \mathrm{C}$ and added aseptically $200 \mathrm{ppm}$ of 2,3,5triphenyltetrazolium chloride solution (TTC) (Sigma, USA) sterilized by membrane filtration and selective supplement (SR183E; Oxoid) containing $20 \mathrm{mg} / \mathrm{L}$ cefoperazone, $20 \mathrm{mg} / \mathrm{L}$ trimethoprim, $20 \mathrm{mg} / \mathrm{L}$ vancomycin and $50 \mathrm{mg} / \mathrm{L}$ cycloheximide. The medium was poured using $20 \mathrm{ml}$ per Petri plate. Aliquots of $0.2 \mathrm{ml}$ of chicken skin sample rinses were spread onto modified Bolton agar plates incubated at $37{ }^{\circ} \mathrm{C}$ for $4 \mathrm{~h}$ and then at $42{ }^{\circ} \mathrm{C}$ for an additional $44 \mathrm{~h}$ period under microaerophilic conditions (5\% oxygen, $10 \%$ carbon dioxide, and $85 \%$ nitrogen) created with the Microarobac System (Probac do Brasil, São Paulo, São Paulo, Brazil). Identification of thermotolerant Campylobacter isolates was based on colony characteristics (magenta color, small, convex, shiny and with perfect edge), Gram stain and growth exclusively in a microaerophilic atmosphere. The Campylobacter colonies were counted and the results expressed as Colony Forming Units per gram of sample (CFU/g).

\section{C. jejuni detection after selective Enrichment}

Five-ml aliquots of sample rinses were enriched with 45 $\mathrm{ml}$ of Bolton broth (Merck) containing selective supplement (SR183E; Oxoid) at $37{ }^{\circ} \mathrm{C}$ for $4 \mathrm{~h}$ and then at $42{ }^{\circ} \mathrm{C}$ for an 
additional $44 \mathrm{~h}$ period under microaerophilic conditions. After this incubation period a portion of enrichment broths was subcultured on Bolton modified agar plates. The plates were incubated at $42{ }^{\circ} \mathrm{C}$ for 24 hours under microaerophilic conditions. Identification of Campylobacter isolates were based on colony characteristics, Gram stain, motility under phase contrast microscopy (Bioval Model L2000A) and by the catalase test. Identification of $C$. jejuni was based on the hippurate hydrolysis test. The results were expressed as presence or absence of $C$. jejuni in 0.5 gram of sample.

\section{Statistical Analysis}

Nonparametric tests of Kolmogorov-Smirnov $(19,28)$ and Mann-Whitney (20) were used to evaluate thermotolerant
Campylobacter counts obtained from fresh, refrigerated and frozen chicken meat samples by direct plating. Case-Control Test by Chi-Square with $5 \%$ of probability (12) was used to analyze the influence of storage conditions and use of selective enrichment broths on the survival and recovery of $C$. jejuni.

\section{RESULTS AND DISCUSSION}

Average plate count results for thermotolerant Campylobacter spp after direct plating of the 30 poultry meat samples analyzed are presented in Table 1. A significant difference for plate counts at a level of $95 \%$ was obtained between results for fresh meat samples as compared to refrigerated and frozen samples.

Table 1. Number of positive samples and average plate count results for thermotolerant Campylobacter spp after direct plating.

\begin{tabular}{|c|c|c|}
\hline Sample & $\begin{array}{c}\text { Number of positive samples/ number of } \\
\text { samples analyzed }(\%)\end{array}$ & Average $\log _{10} \mathrm{CFU} / \mathrm{g}$ \\
\hline Fresh chicken meat ${ }^{(1)}$ & $28 / 30(93.3)^{\mathrm{a}}$ & $3.08^{a}$ \\
\hline Chilled chicken meat ${ }^{(2)}$ & $16 / 30(53.3)^{b}$ & $1.19^{\mathrm{b}}$ \\
\hline Frozen chicken meat ${ }^{(3)}$ & $11 / 30(36.7)^{b}$ & $0.75^{b}$ \\
\hline
\end{tabular}

Different letter in the same column means a significant difference between samples $(\mathrm{P}<0.05)$

(1) Samples analyzed one hour after chicken carcass packaging

(2) Samples kept chilled at $4^{\circ} \mathrm{C}$ for 7 days

${ }^{\text {(3) }}$ Samples kept frozen at $-20^{\circ} \mathrm{C}$ for 28 days

Campylobacter was isolated from all skin chicken samples spiked with approximately $100 \mathrm{CFU}$ of $C$. jejuni ATCC 33291 and it was not isolated from uncontaminated and uninoculated skin chicken samples.

The count reduction found in refrigerated and frozen samples was approximately 1.88 and $2.33 \mathrm{Log} 10 \mathrm{CFU} / \mathrm{g}$ respectively. These results are higher than the ones obtained by Bhaduri \& Cottrell (4) who found a reduction of $0.63 \log _{10}$ $\mathrm{CFU} / \mathrm{g}$ after direct plating of refrigerated chicken skin samples artificially contaminated with $C$. jejuni and a reduction of 1.38 to $2.26 \log _{10} \mathrm{CFU} / \mathrm{g}$ for frozen samples. On the other hand, a five time smaller incidence of $C$. jejuni was detected by Stern et al. (30) in frozen samples as compared to fresh meat samples. Likewise, Georgsson et al. (14) found a significant reduction of 0.65 to $2.87 \log _{10} \mathrm{CFU} / \mathrm{g}$ for Campylobacter counts in samples stored at $-20^{\circ} \mathrm{C}$ for 31 days.

Count reduction after direct plating or after selective enrichment of the chilled or frozen samples might be explained by death or cellular injury which induces Campylobacter cells to assume the "viable but not cultivable" (VNC) form. This form can not be recovered by conventional methods (22).

C. jejuni identification was made only after selective 
enrichment and no significant difference $(\mathrm{P}>0.05)$ was found for $C$. jejuni detection rate from fresh samples or those submitted to low temperatures. Similar results were obtained by Meldrum et al. (22). However, Alter et al. (2) detected a significant reduction rate for $C$. jejuni detection (from 67.4 to $25.6 \%$ ) in 43 turkey meat samples that were held at $0^{\circ} \mathrm{C}$ to $3^{\circ} \mathrm{C}$ for 24 hours.

Lee et al. (17) showed that C. jejuni was able to survive for up to 56 days under frozen storage at $-20^{\circ} \mathrm{C}$, which is the temperature found in most domestic freezers. According to these authors, $C$. jejuni was viable even after a count reduction of approximately $5 \log _{10}$. Georgsson et al. (14) also demonstrated that in spite of a significant Campylobacter count reduction in chicken meat stored at $-20^{\circ} \mathrm{C}$ for 31 days, the counts remained at approximately $3.0 \log _{10} \mathrm{CFU} / \mathrm{g}$. Thus, frozen storage of foods can not be considered a safety assuring procedure when the infection dose for Campylobacter is thought to be about 500 cells.

Fernández and Pisón (11) found 117 (92.9\%) positive results for Campylobacter spp in 126 chicken liver samples analyzed through a selective enrichment method. From these positive samples, $92(73.0 \%)$ were identified as $C$. coli and 25 $(19.8 \%)$ as $C$. jejuni. The authors suggested that $C$. coli could be more resistant to injury resulting from exposure to low temperatures and adverse ambient conditions.

In two samples analyzed in the present work, Campylobacter was detected after direct plating in fresh but not in chilled and frozen samples. However after selective enrichment $C$. jejuni was isolated as much in fresh as in samples kept under refrigerated or frozen storage. Similar results were obtained with two other refrigerated and two frozen samples, where $C$. jejuni was detected only after enrichment.

According to Bolton and Robertson (5) the direct plating technique can be employed in clinical diagnosis laboratories where Campylobacter counts in feces are found to be high, while for studies which are based on low Campylobacter counts, such as in food samples, the enrichment method should be used. The results found in present work showed that the direct plate should be done in parallel with the enrichment method for detection of Campylobacter, specially from refrigerated or frozen foods.

Iceland decided in 2000 to adopt frozen storage of chicken meat as a means to reduce human exposure to Campylobacter. Norway adopted the same strategy in 2001 (14). Nevertheless the results obtained in the present work show that when research is done with selective enrichment, the C.jejuni detection rate in fresh, chilled or frozen chicken meat samples are not significantly different, demonstrating that quite a number of $C$. jejuni cells survive low temperatures. This confirms that chilling or frozen procedures do not assure food safety when concerning this particular microorganism.

The lack of recovery of injured cells by directing plating might be the explanation of the failure of Campylobacter detection or the significant lowering of counts in the refrigerated and frozen chicken meat samples analyzed in this research. However with the selective enrichment technique no significant differences were found for $C$. jejuni detection rate between fresh chicken meat samples and those kept under refrigerated $\left(4^{\circ} \mathrm{C}\right)$ storage for 7 days or those kept under frozen $\left(-20^{\circ} \mathrm{C}\right)$ storage for 28 days, clearly demonstrating that this organism survives these adverse conditions.

\section{REFERENCES}

1. Almeida, P.F.; Serrano, A.M. (1987). Ocorrência de Campylobacter fetus subspécie jejuni em carcaças de frango e suínos. Rev. Microbiol., 18(3), 279-283.

2. Alter, T.; Gaull, F.; Froeb, A.; Fehlhaber, K. (2005). Distribution of Campylobacter jejuni strains at different stages of a turkey slaughter line. Food Microbiol., 22,345-351.

3. Beuchat, L.R. (1987). Efficacy of some methods and media for detecting and enumerating Campylobacter jejuni in frozen chicken meat. J. Appl. Bacteriol., 62,217-221.

4. Bhaduri, S; B. Cottrell. (2004). Survival of cold-stressed Campylobacter jejuni on ground chickens and chicken skin during frozen storage. Appl. Envirom. Microbiol., 70(12),7103-7109.

5. Bolton, F.J.; Robertson, L. (1982). A selective medium for isolating Campylobacter jejuni / coli. J. Clin. Pathol., 35,462-467.

6. Bryan, F.L.; Doyle, M.P. (1995). Health risks and consequences of Salmonella and Campylobacter jejuni in raw poultry. J. Food Prot., 58(3), 326-344. 
7. Butzler, J.P. (2004). Campylobacter, from obscurity to celebrity. Clin. Microbiol. Infect., 10:868-876.

8. Chamovitz, B. N.; Hartstein, A.I.; Alexander, S.R.; Terry, A.B.; Short, P.; Katon, R. (1983). Campylobacter jejuni-associated hemolytic-uremic syndrome in a mother and daughter. Pediatrics, 71(2), 253-256.

9. Chantarapanont, W.; Berrang, M.; Frank, J.F. (2003). Direct microscopic observation and viability determination of Campylobacter jejuni on chicken skin. J. Food Prot., 6, 2222-2230.

10. Donnison, A. (2003). Isolation of Termotolerant Campylobacter Review and methods for New Zealand laboratories. Ministry of Health of New Zeeland. www.moh.govt.nz/moh.nsf.

11. Fernandéz, H.; Pisón, V. (1996). Isolation of thermotolerant species of Campylobacter from commercial chicken livers. Int. J. Food Microbiol., 29, 75-80.

12. Fischer, R.A. (1934). Statistical methods for research workers. Oliver and Boyd, London, England.

13. Franchin, P.R., Aidoo, K.E.; Batista, C.R.V. (2005). Sources of poultry meat contamination with thermophilic Campylobacter before slaughter. Braz. J. Microbiol., 36, 157-162.

14. Georgsson, F.; Porkelsson A.; Geirsdóttir, M.; Reiersen, J.; Stern, N.J. (2006). The influence of freezing and duration of storage on Campylobacter and indicator bacteria in broiler carcasses. Food Microbiol., 23, 677-683.

15. Jones, D. M.; Abbott, J.D.; Painter, M.J.; Suteliffe, E.M. (1984). Comparison of biotypes and serotypes of Campylobacter spp. isolates from patients with enteritis and from animal sources. J. Infect., 9, 51-58.

16. Jфrgensen, F.; Bailey, R.; Williams, S.; Henderson, P.; Wareing, D.R.A.; Bolton, F.J.; Frost, J.A.; Ward, L.; Humphrey T.J. (2002). Prevalence and numbers of Salmonella and Campylobacter spp. on raw, whole chickens in relation to sampling methods. Int. J. Food Microbiol., 76, 151-164.

17. Lee, A.; Smith, S.C.; Coloe, P.J. (1998). Survival and growth of Campylobacter jejuni after artificial inoculation onto chicken skin as function of temperature and packing conditions. J. Food Prot., 61(12), 1609-1614.

18. Leitão, M.F.F.; Taniwaki, M.H.; Uboldi-Eiroa, M.N. (1986). Campylobacter jejuni e $C$. coli no trato intestinal e superfície de carcaças de frango recém abatidos. Col. ITAL,16, 37-47.

19. Kolmogorov, A. (1941). Confidence limits for an unknown distribution function. Annals of Mathematical Statistics, 12, 461-463.

20. Mann, H.B.; Whitney, D.R. (1947). On a test of whether one of two random variables is stochastically larger than the other. Annals of Mathematical Statistics, 18, 50-60.

21. Mead, G. (2004). Campylobacter update - the challenge. Int. Poultry Prod., 12, 4:26-29.

22. Meldrum, R.J.; Tucker, D.; Smith, R.M.M.; Edwards, C. (2005). Survey of Salmonella and Campylobacter of whole, raw poultry on retail sale in Wales in 2003. J. Food Prot., 68(7), 1447-1449.

23. Nachamkin, I.; Allos, B.M.; Ho, T. (1998). Campylobacter species and Guillain-Barré Síndrome. Clin. Microbiol. Rew., 11(3), 555-567.

24. Park, S.F. (2002).The physiology of Campylobacter species and its relevance to their role as foodborne pathogens. Int.J. Food Microbiol., 74, 177-188

25. Paulsen, P.; Kanzler, P.; Hilbert, F.; Mayrhofer, S.; Baumgartner, S.; Smulders, F.J.M. (2005). Comparison of three methods for detecting Campylobacter spp. in chilled or frozen meat. Int.J. Food Microbiol., 103, 229-233.

26. Rosenquist, H.; Sommer, H.M.; Nielsen, N.L.; Christensen, B.C. (2006).The effect of slaughter operations on the contamination of chicken carcasses with thermotolerant Campylobacter. Int.J. Food Microbiol., 108, 226-232.

27. Schiellerup, P.; Krogfelt, K.A; Locht, H. (2008).A comparison of selfreported joint symptoms following infection with different enteric pathogens: effects of HLA-B27. J Rheumatol., 35, 480-487.

28. Smirnov, N.V. (1939). Sur les écarts de la courbe de distribution empirique (Russian/French summary). Matematiceskii Sbornik N.S., 6, 3-26.

29. Solow, B.T.; Cloak, O.M.; P.M. Fratamico. (2003). Effect of temperature on viability of Campylobacter jejuni and Campylobacter coli on raw chicken or pork skin. J. Food Prot., 66, 2023-2031.

30. Stern, N.J.; Green, S.S.; Thaker, N.; Krout, D.J.; Chiu, J. (1984). Recovery of Campylobacter jejuni from fresh and frozen meat and poultry collected at slaughter. J. Food Prot., 47(5), 372-374. 